\title{
Hypohidrotic Ectodermal Dysplasia: A Clinical Case with a Longitudinal Approach
}

\author{
${ }^{1}$ Fabian Calixto Fraiz, ${ }^{2}$ Renato Cordeiro Gugisch, ${ }^{3}$ Bianca Lopes Cavalcante-Leão, ${ }^{4}$ Liliane Moreira Macedo
}

\begin{abstract}
Aim: This paper describes a clinical case of a male with hypohidrotic ectodermal dysplasia submitted to rehabilitation and occlusal dental interventions with follow-up from 3 to 14 years of age.
\end{abstract}

Background: Due to the severe effects on function and esthetics, the clinical manifestations of ectodermal dysplasia exert a negative impact on quality of life. However, oral rehabilitation in childhood poses a challenge due to growth and development.

Case description: A male with hypohidrotic ectodermal dysplasia began dental intervention at the age of 3 years. The clinical and radiographic exams revealed the absence of several primary and permanent teeth and abnormal shape of the primary maxillary incisors. The facial characteristics were compatible with hypohidrotic ectodermal dysplasia, such as a prominent brow, everted lips, flattened bridge of the nose and small vertical facial height. The treatment proposed involved rehabilitation through successive temporary partial dentures, functional orthopedics of the jaws, esthetic reconstruction of the anterior teeth, timely occlusal intervention and preventive actions for the control of dental caries and plaque.

Conclusion: The present case demonstrates that early care plays a fundamental role in minimizing the biopsychosocial consequences of hypohidrotic ectodermal dysplasia and preparing the patient for future oral rehabilitation.

Clinical significance: Although, the literature offers a number of papers describing dental treatment for ectodermal dysplasia, few cases include long-term follow-up and the use of a functional orthopedic appliance in combination with removable dentures in such patients.

Keywords: Case reports, Dental care for children, Denture, Partial, Temporary, Ectodermal dysplasia, Orthodontic appliances, Functional.

How to cite this article: Fraiz FC, Gugisch RC, CavalcanteLeão BL, Macedo LM. Hypohidrotic Ectodermal Dysplasia: A Clinical Case with a Longitudinal Approach. J Contemp Dent Pract 2014;15(6):788-791.

\footnotetext{
${ }^{1,2}$ Associate Professor, ${ }^{3} \mathrm{MSc}$ Student, ${ }^{4}$ Pediatric Dentist

${ }^{1-3}$ Department of Stomatology, Universidade Federal do Paraná, Paraná, Brazil

${ }^{4}$ Private Practice, Curitiba, Paraná, Brazil
}

Corresponding Author: Fabian Calixto Fraiz, Associate Professor, Department of Stomatology, Avenida Prefeito Lothario Meissner 632, Jardim Botânico, Curitiba, Paraná Brazil, Zip Code: 80210-170, Phone: 55413360 4021, e-mail: fabianfraiz@gmail.com

\section{Source of support: Nil}

Conflict of interest: None

\section{INTRODUCTION}

Ectodermal dysplasia is a congenital hereditary disease with extensive, complex disorders caused by the abnormal development of the ectoderm, which compromises the skin, nails, teeth, hair follicles and ectomesenchymal tissues. This condition is categorized as hidrotic and hypohidrotic, depending on the degree of gland dysfunction. Hypohidrotic ectodermal dysplasia is identified by the occurrence of hypotrichosis, hypohidrosis and hypodontia. ${ }^{1-3}$ The phenotype characteristics include a prominent brow, everted lips, flattened bridge of the nose, small vertical facial height, small palatal base, small malar processes and bulging eyes, giving the appearance of aged face. ${ }^{4-7}$

The oral manifestations of ectodermal dysplasia include hyposalivation, difficulty swallowing due to the reduced salivation and the complete or partial absence of teeth. The occurrence of missing teeth affects maxillofacial growth, leading to atrophy and underdevelopment of the stomatognathic system. ${ }^{4}$ The most evident manifestation is the underdevelopment of the alveolar ridge and reduced alveolar bone volume. ${ }^{1,7-10}$

Conventional treatment involves prosthetic and restorative rehabilitation with the aim of improving function, esthetics and occlusion. Although, the characteristics of ectodermal dysplasia are unfavorable to the support of removable dentures and the placement of implants, early oral rehabilitation is important to reducing the resorption of the alveolar process and assisting in the growth of the mandibular bone. ${ }^{2,5,6,8,10-12}$ Moreover, rehabilitation helps attenuate the emotional impact of this condition, with a consequent improvement in quality of life. The use of removable dentures in the early stages of growth has been recommended, ${ }^{6,8,11}$ but few papers report concomitant occlusal management with the use of removable dentures. ${ }^{4}$

This paper describes a case of hypohidrotic ectodermal dysplasia with a multidisciplinary intervention involving pediatric dentistry, temporary partial dentures, functional orthopedics of the jaws and long-term follow-up. 


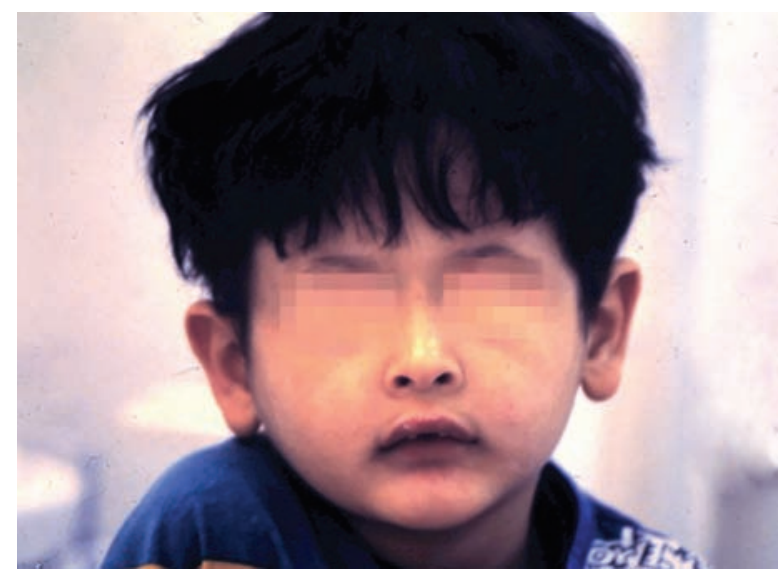

Fig. 1: Initial frontal extraoral view

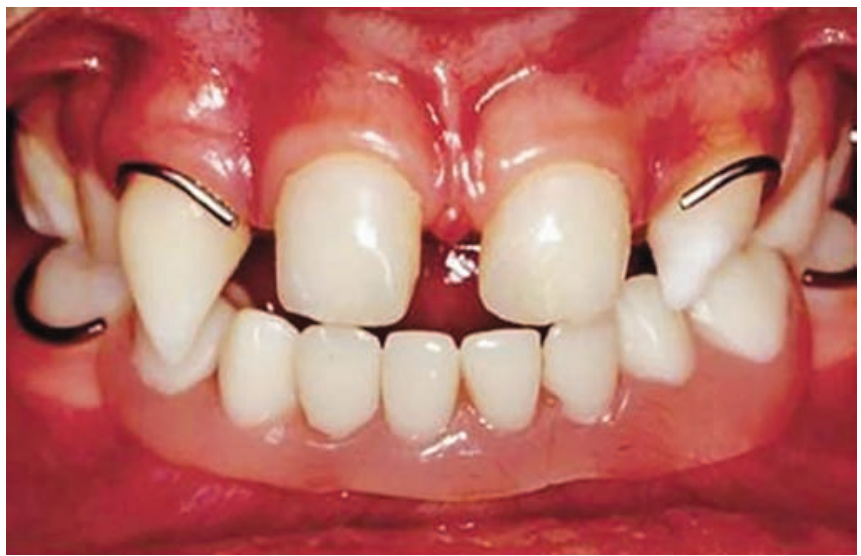

Fig. 3: Esthetic reconstruction of anterior teeth and placement of upper and lower removable dentures

\section{Case Description}

A male patient presented with facial characteristics compatible with ectodermal dysplasia, the absence of several primary and permanent teeth and abnormal shape of the primary maxillary incisors (Figs 1 and 2). Dental intervention began when the child was 3 years of age.

Treatment was carried out in two phases. The aim of the first phase was to improve chewing function and esthetics. Teeth 61 and 51 were reconstructed using direct composite resin restorations and the change in the shape of the canines through filing. Temporary partial dentures were placed (Fig. 3). Preventive and educational measures were established for the control of dental caries and bacterial plaque. The patient remained in follow-up for the next 6 years.

The second phase began with the child was 9 years of age and required the replacement of the dentures. The aim of this phase was to improve the jaw relations. The patient exhibited everted lips, Angle class I molar relationship, deficient alveolar development and significant anterosuperior dental protrusion (Figs 4 to 6). The decision was made to use mucosa-supported functional orthopedic appliances with the concomitant use of removable dentures. The Simões Network 1 slide light

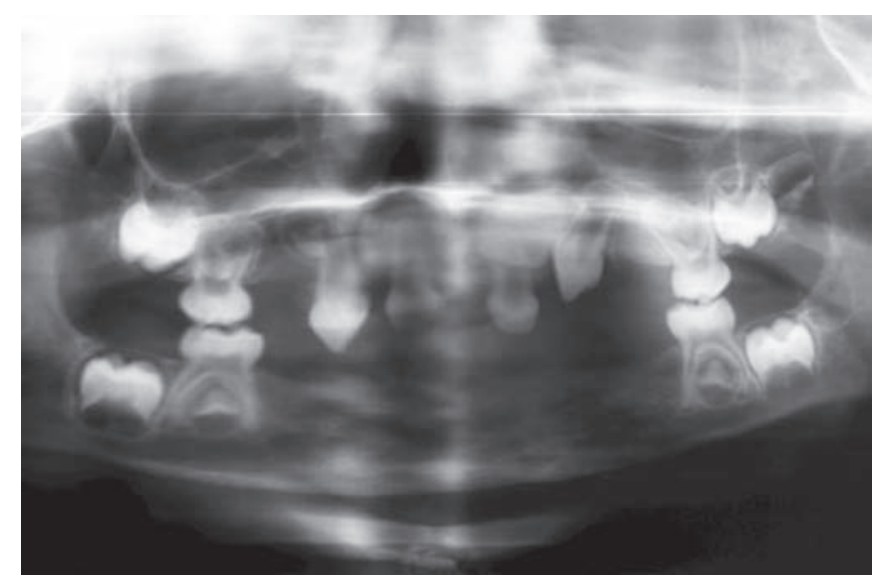

Fig. 2: Initial panoramic radiograph

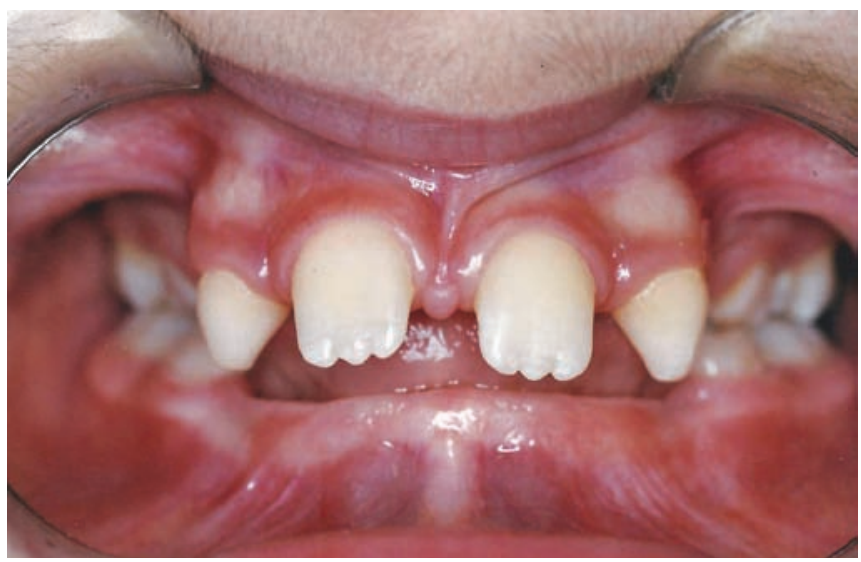

Fig. 4: Onset of phase 2, frontal view

model was used to improve mandible posture and the inclination of the maxillary incisors. Lower lip shields were added to the appliance to broaden the anchorage and strengthen the muscles of the lower lip (Fig. 7). With the eruption of the permanent canines in this phase, the primary canines were esthetically remodeled with composite resin to acquire the shape of lateral incisors.

Until 12 years of age, the orthopedic appliance was replaced with every exchange of dentures. At this age, the inclination of the maxillary incisors was more favorable and the lip was less everted. At 14 years of age, the occlusal relations remained stable (Fig. 8) and the patient was sent for oral rehabilitation.

\section{DISCUSSION}

Dental care for patients with ectodermal dysplasia should involve preventive actions for the control of caries and periodontal disease as well as early rehabilitation. Researchers have recommended the use of removable dentures in the early stages of growth and implantsupported dentures in adolescents. ${ }^{6,8,11,13}$ Dentures improve chewing, swallowing and speech and reduce the resorption of the alveolar process. ${ }^{4}$ Dentures also favor vertical facial growth and jaw relations. ${ }^{7}$ 


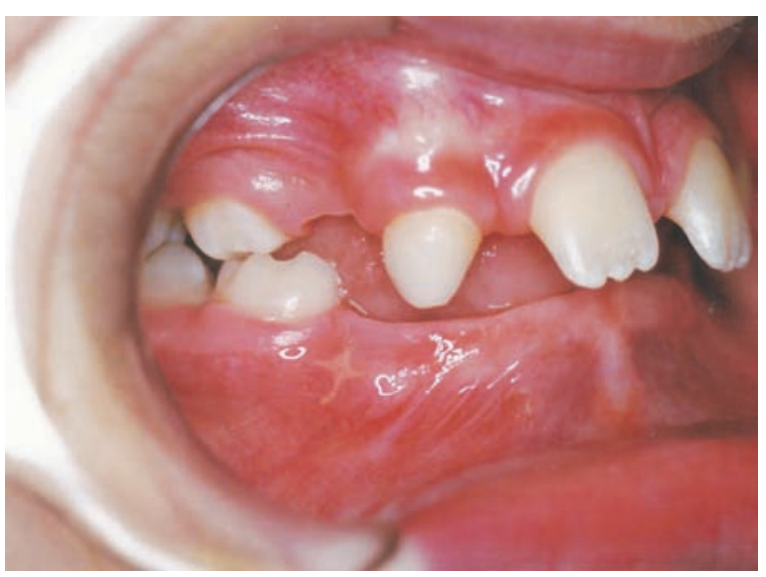

Fig. 5: Onset of phase 2, right side view

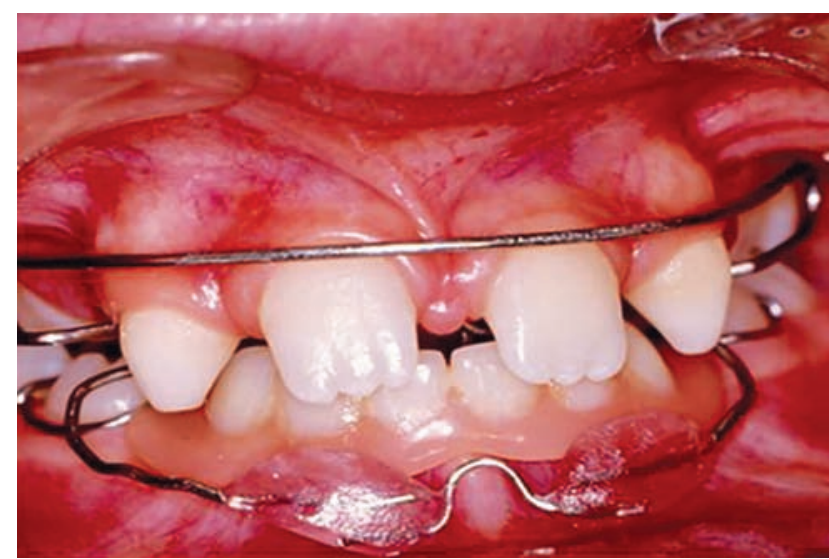

Fig. 7: Onset of phase 2, placement of functional orthopedic appliance

In a recent transverse cephalometric study, Bondarets et $\mathrm{al}^{14}$ suggest that the forward and upward rotation of the mandible is the result of abnormal condyle growth due to the absence of sufficient vertical growth of the alveolar process. Functional orthopedics of the jaws is therefore an important part of treatment in patients with ectodermal dysplasia. ${ }^{4}$ In the case described herein, the child exhibited deficient alveolar development, anterosuperior dental protrusion and everted lips. The use of removable dentures and a functional orthopedic appliance was well accepted by the patient, with frequent changes of these devices to accompany maxillofacial growth. The results were growth of the middle and lower thirds of the face, better mandible positioning and more adequate inclination of the maxillary incisors.

Rehabilitation initiated in childhood can exert a positive influence on sagittal growth of the mandible and the occlusal pattern in individuals with ectodermal dysplasia, leading to an improvement in facial esthetics. $2,4,9,10,12,15$ However, the retention and stability of dentures in difficult to obtain due to the drying out of the oral mucosa and atrophic alveolar ridges. ${ }^{2,9}$ The use of functional orthopedics of the jaws in combination with temporary removable dentures allows changing the bone

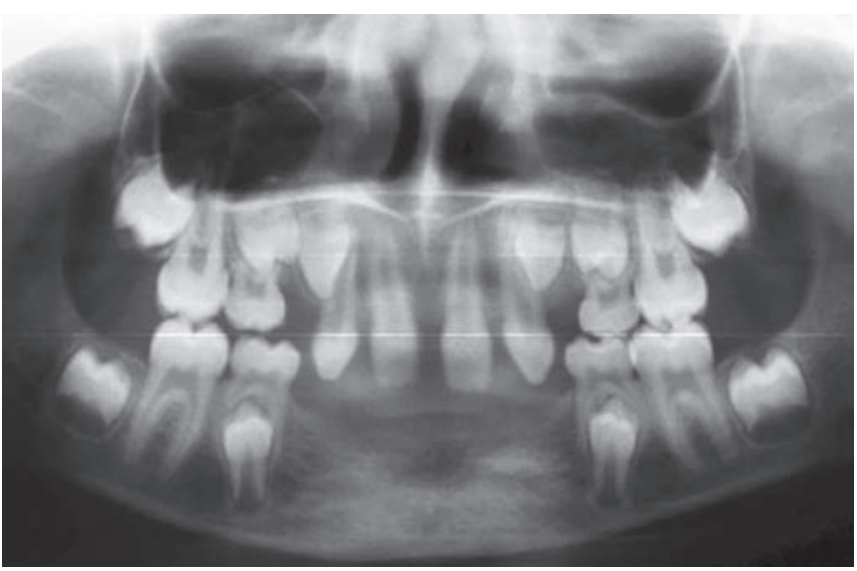

Fig. 6: Onset of phase 2, panoramic radiograph

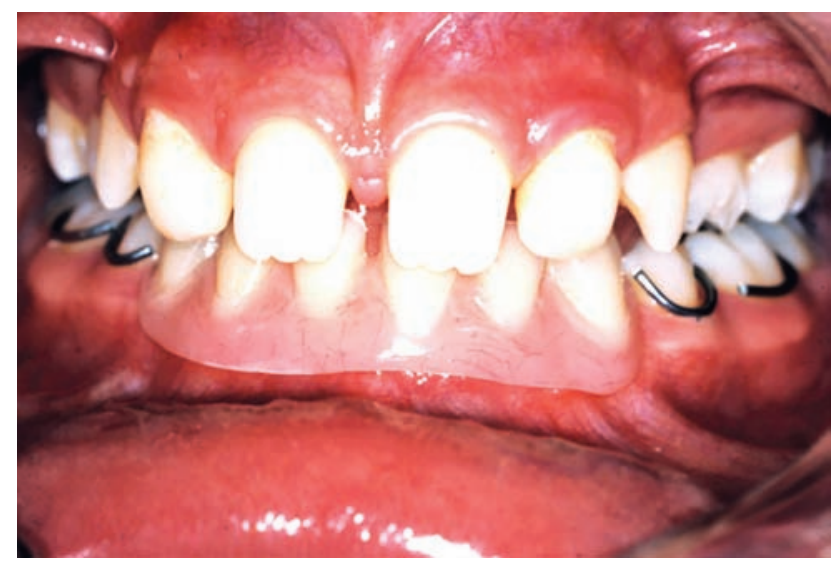

Fig. 8: Frontal view at 14 years of age with removable dentures

development pattern. This protocol also helps prepare the patient for future prosthetic rehabilitation. ${ }^{4}$

\section{CONCLUSION}

Children with ectodermal dysplasia should receive early multidisciplinary dental care, which prepares them for future interventions. Early functional and esthetic interventions also help minimize the impact on quality of life throughout development.

\section{CLINICAL SIGNIFICANCE}

The presence clinical case demonstrates the possibility of early, timely dental care for children with ectodermal dysplasia, with an emphasis on function, esthetics and occlusal management through the use of mucosa-supported appliances.

\section{REFERENCES}

1. Freire-Maia N. Ectodermal dysplasias. Hum Hered 1971;21(4): 309-312.

2. Pigno MA, Blackman RB, Cronin RJ Jr, Cavazos E. Prosthodontic management of ectodermal dysplasia: a review of the literature. J Prosthet Dent 1996;76(5):541-545. 
3. Pinheiro M, Freire-Maia N. Ectodermal dysplasias: a clinical classification and a causal review. Am J Med Gent 1994; 53(2):153-162.

4. Suri S, Carmichael RP, Tompson BD. Simultaneous functional and fixed appliance therapy for growth modification and dental alignment prior to prosthetic habilitation in hypohidrotic ectodermal dysplasia: a clinical report. J Prosthet Dent 2004 Nov;92(5):428-433.

5. Bixler D, Saksena SS, Ward RE. Characterization of the face in hypohidrotic ectodermal dysplasia by cephalometric and anthropometric analysis. Birth Defects Orig Artic Ser 1988; 24(2):197-203.

6. Dellavia C, Catti F, Sforza C, Grandi G, Ferrario VF. Noninvasive longitudinal assessment of facial growth in children and adolescents with hypohidrotic ectodermal dysplasia. Eur J Oral Sci 2008;116(4):305-311.

7. Dellavia C, Catti F, Sforza C, Grandi G, Ferrario VF. Craniofacial growth in ectodermal dysplasia. An 8 years longitudinal evaluation of Italian subjects. Angle Orthodontist 2010;80(4):733-739.

8. Sweeney IP, Ferguson JW, Heggie AA, Lucas JO. Treatment outcomes for adolescent ectodermal dysplasia patients treated with dental implants. Int J Paediatr Dent 2005;15(4):241-248.
9. Tarjan I, Gabris K, Rozsa N. Early prosthetic treatment of patients with ectodermal dysplasia: a clinical report. J Prosthet Dent 2005;93(5):419-424.

10. Worsaae N, Jensen BN, Holm B, Holsko J. Treatment of severe hypodontia-oligodontia-an interdisciplinary concept. Int J Oral Maxillofac Surg 2007;36(6):473-480.

11. Bhalla G, Agrawal KK, Chand P, Singh K, Singh BP, Goel $\mathrm{P}$, Alvi HA. Effect of complete dentures on craniofacial growth of an ectodermal dysplasia patient: a clinical report. J Prosthont 2013;22(6):495-500.

12. Alcan T, Basa S, Kargu 1B. Growth analysis of a patient with ectodermal dysplasia treated with endosseous implants: 6-year follow-up. J Oral Rehabil 2006;33(3):175-182.

13. Hekmatfar S, Jafari K, Meshki R, Badakhsh S. Dental management of ectodermal dysplasia: two clinical case reports. J Dent Res Dent Clin Dent Prospect 2012;6(3):108-112.

14. Bondarets N, Jones RM, McDonald F. Analysis of facial growth in subjects with syndromic ectodermal dysplasia: a longitudinal analysis. Orthod Craniofac Res 2002;5(2):71-84.

15. BalC, Bal BT, Casela L, Tufekçioglu D. Treatment considerations for a patient with hypohidrotic ectodermal dysplasia: a case report. J Contemp Dent Pract 2008 March;9(3):128-134. 